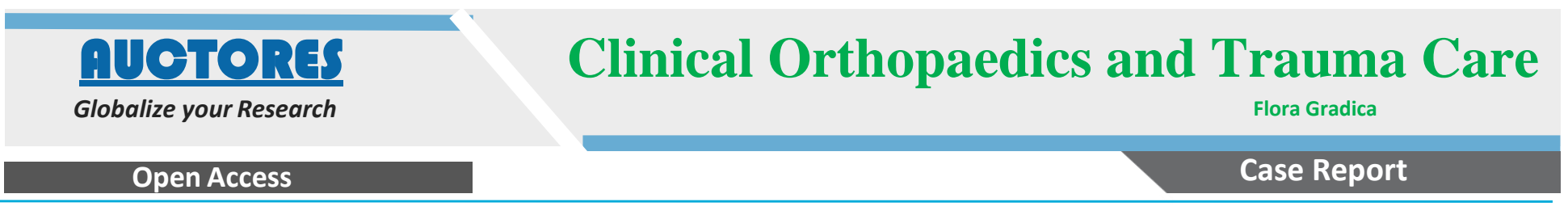

\title{
Spontaneous Pneumothorax in Covid-19 Pneumonia. Case report
}

Fadil Gradica, Daniela Xhemalaj, Lutfi Lisha, Dhimitraq Argjiri, Alma Cani, Fahri Kokici, Flora Gradica*, Valbona Rexha ,Aishe Lala, Donika Lala

University hospital of lung diseases "Shefqet Ndroqi", public Pharmacy Service, Odontology Service Tirana, Albania.

*Corresponding Author: Fadil Gradica, University hospital of lung diseases "Shefqet Ndroqi", public Pharmacy Service, Odontology Service Tirana, Albania.

Received date: August 11, 2020; Accepted date: October 16, 2020; Published date: October 23, 2020.

Citation: F Gradica. (2020) It Just Takes One Phone Call: Simultaneous Activation to Reduce Referral Times. Clinical Orthopaedics and Trauma Care. 2(2); DOI:10.31579/2694-0248/010

Copyright:@2020 Fadil Gradica, This is an open-access article distributed under the terms of the Creative Commons Attribution License, which permits unrestricted use, distribution, and reproduction in any medium, provided the original author and source are credited.

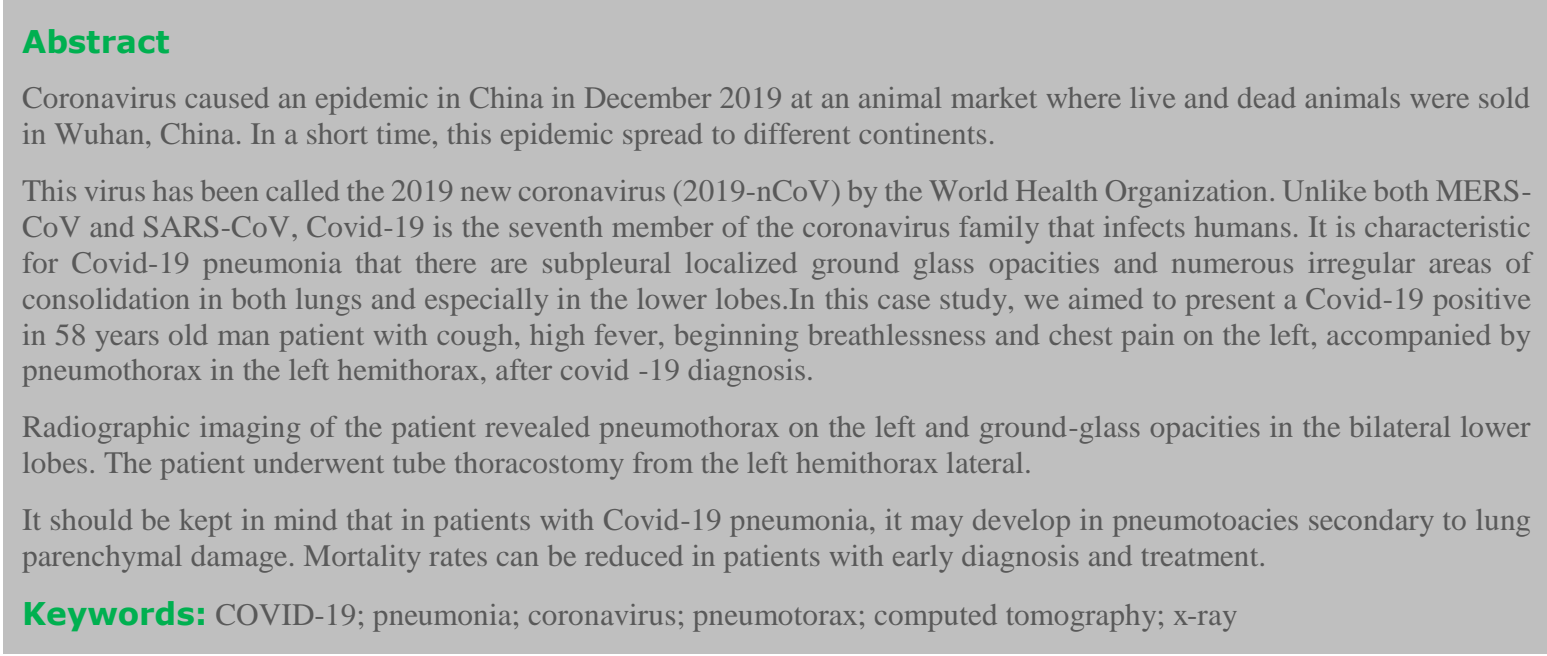

\section{Introduction}

A new case of Coronavirus infection, occurred in Wuhan, in China, in December 2019. On January 2020, this corona virus identified, was called 2019-nCoV [1].

Coronaviruses are enveloped RNA viruses that cause respiratory, enteric, hepatic, and neurological diseases that are common among birds, humans, and other mammals [2].

Up to now, are known six coronavirus species to cause human disease. The four common types cause common cold symptoms. The other two types of severe acute respiratory syndrome coronavirus (SARS-CoV) and Middle East respiratory syndrome coronavirus (MERS-CoV) are of zoonotic origin and can cause fatal diseases [3].

Although the mortality of Covid-19 is lower than that of SARS-CoV and MERS-CoV, the number of confirmed Covid-19 cases has increased significantly [4].

As of August 9, 2020, a total of Coronavirus Cases 19,918,709 and 731,718 deaths were reported worldwide $[5,6]$.

Radiological imaging plays an important role in the diagnosis and treatment of pneumonia, which is the clinical presentation of Covid-19 [7]. Chest radiographs show low-density pneumonia foci (viral pneumonia), which mostly involve bilateral mid-lower zones in this disease.

\section{Case Report}

A 58-year-old male patient was admitted in July to the emergency department with complaints of fever, cough, shortness of breath and increased pain in the left hemithorax. His general condition was not good, inconscious, noncooperative and nonorientated with diabetes with insulinotherapy since 3 years and hypertension equilibrated. Blood pressure arterial $150 / 90 \mathrm{mmHg}$, pulse $92 / \mathrm{min}$, respiratory rate $20 / \mathrm{min}$, fever $38.5^{\circ} \mathrm{C}$, oxygen saturation (SpO2) with finger probe was $50 \%$.

In blood tests WBC: 13.06 103/uL, NEU lymphocyte: 1.59 103/uL, HGB: 14.4 g/dL, HCT: 42.4\%, PLT 188 103/uL, fasting blood sugar: $137.7 \mathrm{mg} / \mathrm{dL}$, urea: $34.3 \mathrm{mg} / \mathrm{dL}$, Creatinine: $0.91 \mathrm{mg} / \mathrm{dL}$, ALT (SGPT): $13 \mathrm{U} / \mathrm{L}, \mathrm{AST}$ (SGOT): $11 \mathrm{U} / \mathrm{L}, \mathrm{LDH}: 150 \mathrm{U} / \mathrm{L}$.

On radiological examination of the patient, consolidation and ground glass images were observed in the bilateral lower lobes and the accompanying left pneumothorax (Figure 1, 2, 3, 4). 

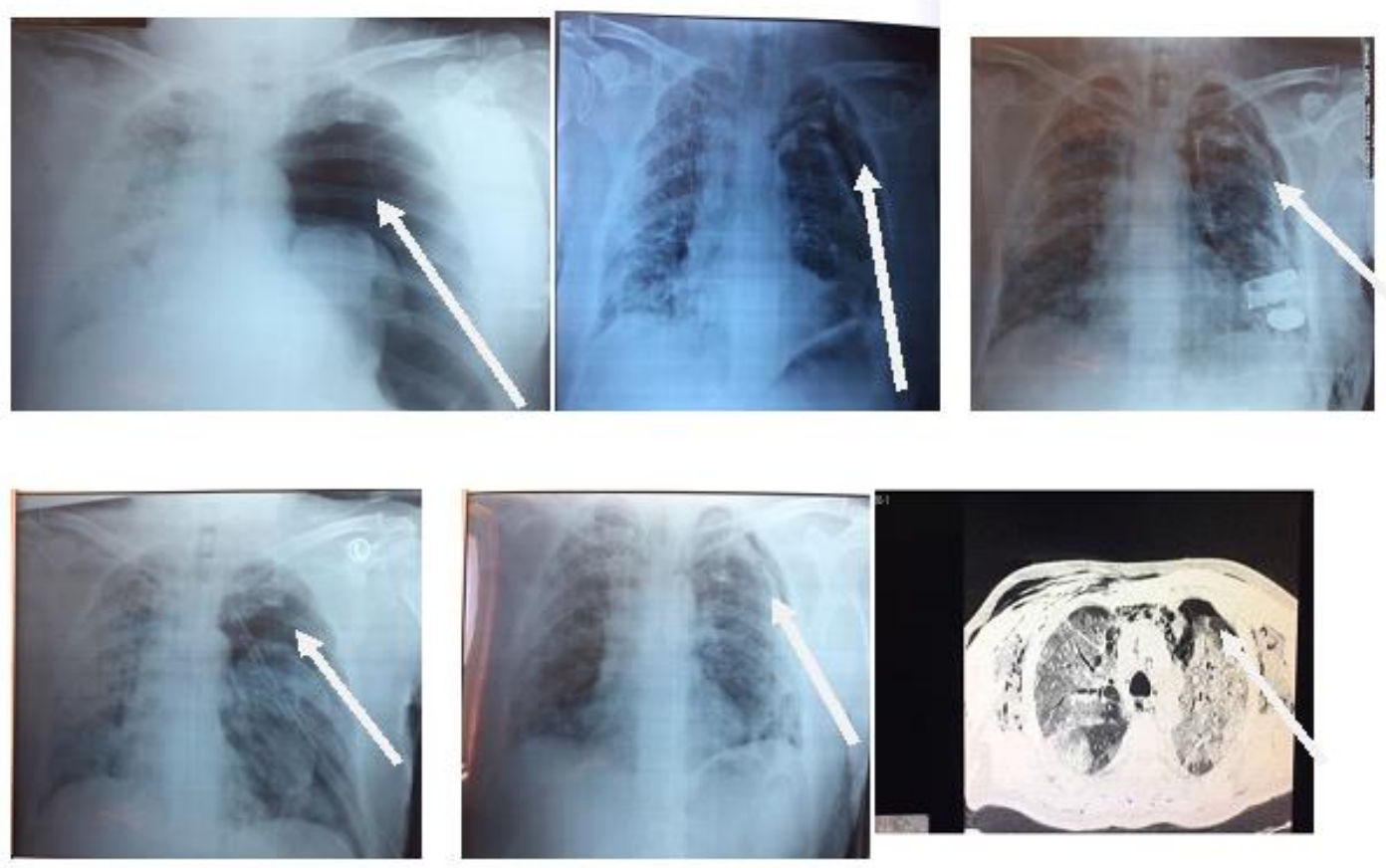

Figure. $(1,2,3,4,5,6)$ Posteroanterior chest x-ray and drenaige tube.

The patient was admitted in the intensive care unit and the ts situation was improving day by day.but 4 days after the hospitalisation a left pneumothorax occured

Covid-19 positive was detected in the polymerase chain reaction analysis (PCR).

Other vital signs were observed stably. There was no reproduction in the blood culture of the patient.

The control arterial blood gas was pH 7.32, PCO2 60.4, PO2 78.6. Vital findings remained stable. Six after the hospitalisation a left pneumothorax occured.In the linea axillaris medioanterior, space 4-5, with local anesthesia, a pleural dranaige was performermed.

Treatment and follow-up of the patient continues.

\section{Discussion}

The new coronavirus was identified and isolated by three groups of Chinese scientists. A consortium coordinated by W. Tan from the China Centers for Disease Control and Prevention (China CDC) achieved eight complete viral genome sequences by sequencing from RNA isolation and bronchoalveolar lavage fluid (BALF) in nine patients [8].

The China Centers for Disease Control and Prevention (China CDC) identified 44672 Covid-19 positive patients on February 14. 965 of them $(2.2 \%)$ were under 20 and the mortality rate in this age group was $0.1 \%$. $77.8 \%$ of the patients reported that they were between the ages of 30 and 69 [9].

Our patient was a 24-year-old young healthy man with no additional disease, previous operation and history of pneumothorax. In his complaints, he had high fever, cough, shortness of breath, and chest pain on the left.

Currently, the RT-PCR test is used as a standard in the definitive diagnosis of Covid-19 infection despite false negativity rates.
Sana $S$ et al. They investigated imaging findings in 919 Covid-19 positive patients and detected ground-glass densities in $88 \%$ of cases. $87.5 \%$ of parenchymal attitudes were observed to be bilateral. None of them encountered pneumothorax [10].

\section{Conclusion:}

In this study, we present a 58-year-old man patient with Covid-19 pneumonia and pneumothorax. We discussed the patient and his radiological findings in the light of the literature. Pneumothorax may develop in Covid-19 pneumonia due to alveolar damage. This can cause increased mortality and morbidity. For this reason, pneumothorax should be kept in mind in the treatment and follow-up of Covid-19 infection.

\section{Conflict of Interest}

All authors declare that they have no conflict of interest.

\section{Financial Support}

No financial support was recieved for study.

\section{Author Contributions}

All authors contributed equally.

\section{References:}

1. Li Q, Guan X, Wu P, et al. (2020) Early transmission dynamics in Wuhan, China, of novel coronavirus infected pneumonia. $\mathrm{N}$ Engl J Med 382: 1199-1207.

2. Weiss SR, Leibowitz JL. (2011) Coronavirus pathogenesis. Adv Virus Res 81: 85-164.

3. Cui J, Li F, Shi ZL. (2019) Origin and evolution of pathogenic coronaviruses. Nat Rev Microbiol 17: 181-192.

4. WEi Zhao, Zheng Zhong, Xingzhi Xie, et al. (2020) Relation Between Chest CT Findings and Clinical Conditions of Coronavirus Disease (COVID-19) Pneumonia: A Multicenter Study. American Journal of Roentgenology 214: 1072-1077. 
5. https://www.worldometers.info/coronavirus/?utm_campaign=h omeAdvegas 1?

6. World Health Organization Coronavirus disease 2019 (COVID19) Situation Report-74 (2019).

7. Harald Brüssow. (2020) The Novel Coronavirus-A Snapshot of Current Knowledge, Microbial Biotechnology 13: 607-612.

8. Report of the WHO-China Joint Mission on Coronavirus Disease (COVID-19) (2019).
9. Wenjie Yang, Fuhua Yan. (2020) Patients with RT-PCRconfirmed COVID-19 and Normal Chest CT. Radiology 295.

10. Sana Salehi, Aidin Abedi, Sudheer Balakrishnan. (2019) Coronavirus Disease 2019 (COVID-19): A Systematic Review of Imaging Findings in 919 Patients. American Journal of Roentgenology, 1-7.
Ready to submit your research? Choose Auctores and benefit from:

* fast, convenient online submission

* rigorous peer review by experienced research in your field

* rapid publication on acceptance

* authors retain copyrights

* unique DOI for all articles

* immediate, unrestricted online access

At Auctores, research is always in progress.

Learn more www.auctoresonline.org/journals/clinical-orthopaedicsand-trauma care -- 